\title{
Research on the Role of Social Organizations in Labor Dispute Mediation
}

\author{
De-Ming LEI ${ }^{1 a^{*}}$, Hong-Zhen LIN ${ }^{2 b}$ \\ ${ }^{1}$ School of law and Economics, Wuhan University of Science and Technology Wuhan, China distinct \\ addresses: 947 He Ping Street, Hubei Wuhan 430081, China \\ leihaohaoyun@126.com \\ ${ }^{2}$ School of Management, Wuhan University of Science and Technology Wuhan, China Distinct \\ addresses: 947 He Ping Street, Hubei Wuhan 430081, China \\ linjingziran@126.com
}

Key words: labor relations, coordination, social organization

\begin{abstract}
The purpose of this paper is to research the role of social organizations in labor dispute mediation. Using the method of document study and investigation obtained necessary data in order to understand the labor dispute mediation. labor disputes as one of the social problems of public administration, the universality and particularity principle, various methods of social organizations involved in a labor dispute disposal way of social organizations can be used to take part in public management. The paper analyzes the problems of labor dispute mediation. The conclusion is that the basic meaning of social coordination mechanism is to emphasize the formation of public decision-making through social organizations and public participation, and to achieve the purpose of protecting the basic labor rights of citizens. Therefore, Taking social coordination as the means of dispute resolution and the channel of expression of interest demands is considered as one of the important propositions of constructing a harmonious society.
\end{abstract}

\section{Introduction}

The social coordination mechanism of labor relations is the mechanism formed by the direct action of the non-government and non-laborers individual members on labor relation. In the coordination mechanism of labor relations in China, except for the market mechanism and the government mechanism, belong to the social coordination mechanism. This mechanism has many manifestations in specific form, including labor and capital Arbitration mechanism, worker participation mechanism, social responsibility movement mechanism, civil mediation mechanism, etc. It is a coordination mechanism involving a wide range.

Labor relations and social coordination mechanism to override the main parties on the power or the organization as the subject is based on coordination, coordination of labor relations within the subject of participation, cooperation and consultation on the interests of the labor relations [1]. Both sides are the stakeholders of labor relations, and the complete withdrawal of either party not only seriously damages the interests of the other party, but also does serious harm to their own interests.

\section{Features of Social Organizations Participating in the Coordination of Labor Relations}

\section{First, Non-Mandatory}

In the social coordination mechanism of labor relations, the coordinating subject is the non-stakeholder in the labor relation, and the social organization is the third party out of the labor relation. Social organizations do not have special enforcement agencies, but rely on mutual trust and contractual compliance to achieve consensus.

The social coordination mechanism of labor relations can be negotiated with tit for tat. In the game of Union and enterprise, trade unions usually ask for higher wages and higher labor benefits. Firms may also be forced to reduce their employees by forcing them to decrease their wages. Mutual concessions and compromises are needed and mutual interests can be taken into account. 


\section{Second, Negotiability}

The social coordination mechanism of labor relations can be negotiated or negotiated with tit for tat. In the negotiations between social organizations and enterprises, they usually require higher wages and higher labor benefits. Firms may also be forced to reduce their employees by forcing them to increase their wages. Mutual concessions and compromises are needed and mutual interests can be taken into account.

\section{Third, Social Welfare}

The social coordination mechanism of labor relations is a coordination mechanism between non-governmental organizations and non-working individuals. These mechanisms have no administrative power and have no administrative binding force on the subject in the labor relations [2]. The coordination mechanism of labor relations and social binding mainly from morality and public opinion pressure generated by the material benefit and the loss of spiritual interests, but the interests of more social, rather than direct market interest.

\section{Labor Disputes Disposal Methods of Social Work Organizations}

\section{Firstly, Prevention in Advance}

Prevention aims to improve the current labor relations through a service object of social workers guide and help the environment, improve the ability of both sides of labor dispute self-determination, prevent dispute and avoid possible disputes. Among them, the most effective way is to take the community social work implanted into the employer or a local such as the Industrial Park, by the social work organization, coordination, guidance, education, propaganda and employers self-determination combination, to adjust measures to local conditions to form and improve the employer or the local labor relations benign environment. In addition, it can also take the form of group social work and social work mode of specific objects to provide psychological counseling, corrective action and other services, can kill the dispute and dredging, intensification of the signs in the bud.

\section{Secondly, Deal with the Situation}

In the process of dealing with matters, through the involvement of social workers, it can effectively improve the efficiency of resolving conflicts and disputes, and even fill the lack of services in the process of government departments [3]. Intervention is the most effective method of social work, for the specific case, social workers and its affiliated organizations through the investigation of both sides of the background, analysis and diagnosis of disputes node, propose solutions, help the two parties to ease pent up emotions, no doubt, correction of deviant behavior, thus rationally into peace, negotiation process, to resolve the contradictions and case. In the case of the intervention process, participating in social work intervention to identify candidates for different regions and different practices, or by government departments directly from the social work in social positions in the assignment, and some are appointed by a partnership with government social organizations, or by the parties according to their own needs in all aspects of the Commission; social authority around the practice are different, some social contradictions and disputes in only one party psychological counseling work, workers and some disputes and also participate in the negotiation mediation.

\section{Thirdly, Afterwards Relief}

The main purpose of relief to both sides especially vulnerable party (such as labor disputes) is to provide reasonable solution to international humanitarian assistance, so that the parties can rapidly modify itself into the society, to restore the original or improve the current state of life, such as providing employment guidance, skills training and other help[4]. In reality afterword's relief is like a safety net, to ensure that the local balance of dispute resolution after the original break to recover quickly, effectively avoid a party personnel because life cannot restore the original of the negative 
consequences of individual and society. Case studies include social work, group social work and community social work.

\section{The Role of Social Work Organizations in the Management of Labor Disputes}

\section{Firstly, It Is Conducive to Rational Allocation of Social Work Resources.}

Social organizations and administrative agencies have their own management structure and operation system. It can provide the perfect service for social management output, effectively improve the professional social workers professional level and social work service quality. Social organizations involved in a labor dispute disposal can provide professional social workers or social worker team for the party candidate list according to the characteristics and needs of the parties; the office of government departments in the presence of circumstances can also be through consultation and recommend ways to government departments to be appointed according to the social worker [5]. Therefore, compared with individual social workers' "going alone", the social worker organizations have the advantages of flexibility, efficiency and standardization in the choice of service subjects.

\section{Secondly, It Can Provide More Comprehensive Services to the Parties Involved in the Dispute.}

The parties often lack information in embarrassment, difficult to fully grasp the effective information of social choice, but also in dispute intense compression of mental state. Selecting the appropriate social workers may avoid the selection of a difficult situation [6]. However, the involvement of social work organizations can effectively alleviate the party's doubt on the professional competence of individual social workers, and reduce the external costs caused by social worker selection.

Human needs are roughly related to three aspects, such as physiology, psychology and social adaptation, and these three aspects are the most concerned issues in social work [7]. Due to social organizations as individual social workers provide social work service of the "rear", to provide the necessary support for individual workers, such as occupation skill training, the sharing of information resources in the organization and deployment of personnel, the organization and the China Unicom counseling and other aspects of employment, social workers, organizations can improve individual working ability; to dispute the parties concerned, it can obtain more comprehensive, more intimate, more subtle services from social organizations [8].

The involvement of social workers objectively helps to improve the lack of information and the cost of external transactions for workers. In general, the contact and access to capital relations information means more employers in less disputes, when executed in limited means to deal with disputes, and the urgent question ability, executed when limited means to deal with in dispute, extreme behavior, easily lead to a series of negative events is not conducive to the legitimate interests of the appeal and relief workers ${ }^{[9]}$. Extreme behavior easily lead to a series of negative events and not conducive to the legitimate rights and interests of workers complaints and relief.

\section{Thirdly, It Is Good for Social Harmony.}

For society, social work belongs to flexible management, mainly involved in public management through persuasion, propaganda, suggested that non coercive means; and government intervention are rigid management, carrying out public management mainly through the regulations and administrative law enforcement and other coercive means to deter. Flexible management can make up for the lack of rigid management, effective prevention of disputes from its rigid management derived, also can be woven rigid management soft landing "safety net", also can be produced by the non-compulsory way dispute prevention. Therefore, the intervention of social worker labor disputes disposal can properly resolve the dispute case from the micro view, to help the parties to restore life balance [10]. It can effectively improve the whole social labor relations, to create a harmonious and win-win employment environment. 


\section{Conclusion}

The construction of harmonious labor relations is the starting point and goal of social justice. Harmonious labor relations are not without contradiction and conflict, but have a normal channel for resolving contradictions and conflicts. In the process of developing socialist market economy, which based on the interests of labor relations contradiction is universal, and sometimes more intense, but these contradictions can equal consultation mechanism through labor relations between the two sides to solve. We must establish rules, provide a mechanism to balance the interests of a system to solve the conflicts in labor relations because of the benefit, let these contradictions and conflicts can be accommodated in the framework of the system, in a systematic way to solve. It should be pointed out that the construction of socialist harmonious labor relations is also a long-term process.

\section{Acknowledgement}

This research was financially supported by Project research of Hubei non-profit organization research center, 2016 The Role and Status of Social Organizations in the Construction of Harmonious Labor Relations. No. HBNPO2016ZD006

This research was financially supported by Project Hubei Province Education Department Foundation: Study on legal guarantee for flexible employment of workers in excess capacity industry in Hubei Province. No. $17 \mathrm{Y016}$

\section{Reference}

[1]He yuan. Social organization intervention and collective labor relations operation. An exploratory model of labor dispute mediation [J]. China human resources development, 2015 (15): 93-96.

[2] Zhang Baifeng. Actively participate in social management innovation to build for the mediation work pattern of [J]. Law, 2012 (8): 92-95.

[3] Pan Xiuhua. Analysis of social organizations' participation in resolving social conflicts [J]. Theory research, 2016, No.189 (2): 158-162.

[4] Xu Yinxiang, Cheng Gang, Yuan Wei. Study on the mediation of labor disputes at the grassroots level under the great mediation pattern [J]. Shandong human resources and social security, 2016 (3): 26-29.

[5] Ji Ji. Study on the path of trade unions to mediate labor disputes [J]. Journal of Beijing trade union cadre college, 2015, 33 (1): 14-17.

[6] Chen Chen. Judging from the case of mediation $\backslash$ Neutrality and specialization of civil mediation organizations [J]. Chinese workers, 2015 (11): 8-11.

[7], Wang Ke. Discussion on enterprise labor and labor organization management [J]. China Hi tech enterprises, 2015 (1): 175-176.

[8], Yang Lijun, Tang Ling. Research on the adjustment mechanism of labor relations in China based on the method of monism [J]. Enterprise economy, 2017 (2): 88-95.

[9], Zhang Yuhong. Countermeasures and suggestions for positive interaction between employee rights protection and mass media [J]. Chinese workers, 2016 (5): 35-40.

[10] Lin Li. Taking the management of wages as the focus and actively building a harmonious labor relationship [J]. China human resources and social security, 2016 (2): 54-55. 